\title{
Deformation and Anchoring of AA 2024-T3 rivets within thin printed circuit boards
}

Maria Clara Farah Antunes Vilas Boas, Camila Fernanda Rodrigues, Lucian-Attila Blaga, Jorge Fernandez dos Santos and Benjamin Klusemann

Maria Clara Farah Antunes Vilas Boas. Institute of Materials Mechanics, Solid State Materials Processing, Helmholtz-Zentrum Geesthacht, Geesthacht, Germany

Department of Materials Engineering, Federal University of São Carlos, São Carlos, Brazil

Camila Fernanda Rodrigues. Institute of Materials Mechanics, Solid State Materials Processing, Helmholtz-Zentrum Geesthacht, Geesthacht, Germany

Lucian-Attila Blaga. Institute of Materials Mechanics, Solid State Materials Processing, Helmholtz-Zentrum Geesthacht, Geesthacht, Germany

Corresponding author: Blaga Lucian-Attila. E-mail address: lucian.blaga@hzg.de

Jorge Fernandez dos Santos. Institute of Materials Mechanics, Solid State Materials Processing, Helmholtz-Zentrum Geesthacht, Geesthacht, Germany

Benjamin Klusemann. Institute of Materials Mechanics, Solid State Materials Processing, Helmholtz-Zentrum Geesthacht,

Geesthacht, Germany

Institute of Product and Process Innovation, Leuphana University of Lüneburg, Lüneburg, Germany

Abstract. This work evaluates the viability of applying Friction Riveting as an alternative for the assembly of components on printed circuit boards (PCBs). The popular press-fit technology for assembling components on PCBs consists of a pin inserted tightly into a relatively smaller hole, resulting in good electrical and mechanical properties. However, some limitations are highlighted, such as numerous processing steps and the need for predrilled holes. Friction Riveting is based on mechanical fastening and friction welding principles, where polymeric components are joined with metallic rivets through frictional heating and pressure. The main benefits of using Friction Riveting in PCBs compared with fit-press are (i) a reduced number of processing steps and (ii) shorter joining cycles, because there is no pre-drilling involved with fasteners anchored within the PCB in a single step. The joints were manufactured using $5 \mathrm{~mm}$ diameter AA-2024-T3 rivets and $1.5 \mathrm{~mm}$ thick glassfiber-reinforced epoxy laminates (FR4-PCB). It is shown for the first time that it is possible to deform metallic rivets within thin composite plates at a reduced diameterto-thickness ratio. The feasibility study followed a one-factor-a-time approach for parameter screening and optical microscopy assessed joint formation of the deformed rivets inside the laminates through volumetric ratio (VR). The joints present significant deformation $(\mathrm{VR}=0.5)$ at the tip of the rivet inserted into overlapped PCBs plates, with thicknesses below $3.0 \mathrm{~mm}$, which is considered the lowest achieved so far with Friction Riveting.

Keywords. Friction Riveting, Printed Circuit Board, Hybrid Thermoset-metal Joints, Joint Formation,

Mechanical Anchoring

\section{Introduction}

Most modern electronic circuits in the industry are manufactured using printed circuit boards (PCBs). The PCBs are produced from glass-fiber-reinforced epoxy laminate with multiple copper layers. The cooper layers link the electronic components together, forming a circuit. The present work intends to contribute to the mounting techniques for PCB post assembly. For mounting electronic components in PCBs, fastening processes are commonly used based on drilling holes through the board to place them or attach various electrical components [1].

The Friction Riveting technique is proposed as an alternative to the press-fit technology for the assembly of components in PCBs. The frequently used press-fit technology for assembling of components on PCBs is a solder-free electrical assembly process. A pin is generally inserted tightly into a slightly smaller hole; the interference generated is enough 
to hold both parts in place and results in very good electrical and mechanical properties [2]. However, this method has some limitations, such as the number of processing steps, the need for pre-drilled holes on both sides of the plate, the use of an anvil, and connecting/mating screws [3].

Given the limitations of press-fit fasteners, Friction Riveting has been identified as a potentially advantageous alternative. The main benefits of using Friction Riveting in PCBs are the reduced number of process steps and shorter joining cycles, no need for pre-drilling and access form one single sides of the plate only. The friction-riveted fastener is directly anchored within the PCB through a single entrance with no mating screw required, leading to a decrease in component weight.

Friction Riveting is a metal-polymer hybrid joining technology, developed and patented in 2007 by the HelmholtzZentrum Geesthacht (HZG) [4-5]. The method is based on the principles of mechanical fastening and friction welding. One or more thermoplastics or composite components are joined with a cylindrical metallic rivet through frictional heating and pressure, where the former causes the rivet to plasticize and deform [6-10]. The feasibility of Friction Riveting has been demonstrated for a substantial number of material combinations and applications, but never for electronic applications. Studies have been conducted with hybrid friction-riveted joints of different aluminum alloys with unreinforced thermoplastics (Polyetherimide, PEI [11], and Polycarbonate, PC [8]). Additionally, the technique was also successfully applied in reinforced polymer, carbon, and fiberglass laminates (e.g., GF-PEI [12]; CF-PEEK [7], GF-PA6 [9], GF-P [10]) joined with titanium and aluminum rivets.

This work aims to study the joint formation of AA-2024-T3 rivets and FR4 laminates with single and double copper layers. The feasibility study follows a one-factor-a-time (OFAT) approach for parameter screening and optical microscopy (OM) to assess the joint formation of deformed rivet inside the laminates through the volumetric ratio (VR). The temperature evolution was recorded to understand the results of joints' microstructure and local mechanical properties. The global mechanical behavior of the frictionriveted joints was analyzed by tensile testing.

\section{Materials and Methods}

\subsection{Rivets}

AA-2024-T3 extruded plane rivets were used with a diameter of $5 \mathrm{~mm}$ and a length of $60 \mathrm{~mm}$. Table 1 presents the chemical composition of AA-2024-T3. The melting point of this aluminum alloy is between $502^{\circ} \mathrm{C}$ (solidus) and $638^{\circ} \mathrm{C}$ (liquidus) [13]. Fig.1 illustrates the microstructure and microhardness of the rivet material. The microstructure is characterized by elongated grains due to the extrusion process. A homogeneous hardness distribution is present with values around $155 \mathrm{HV}$.

\begin{tabular}{llllllllll}
\hline Element & $\mathrm{Cu}$ & $\mathrm{Mg}$ & $\mathrm{Mn}$ & $\mathrm{Fe}$ & $\mathrm{Zn}$ & $\mathrm{Si}$ & $\mathrm{Ti}$ & $\mathrm{Cr}$ & $\mathrm{Al}$ \\
\hline wt. \% & $3.8-$ & $1.2-$ & $0.3-$ & 0.5 & 0.25 & $<0.5$ & 0.15 & 0.1 & bal. \\
& 4.9 & 1.8 & 0.9 & $\mathrm{Max}$ & $\mathrm{Max}$ & & $\mathrm{Max}$ & $\mathrm{Max}$ & \\
\hline
\end{tabular}

Table 1. Chemical Composition of AA2024-T3 rivets [13]. 

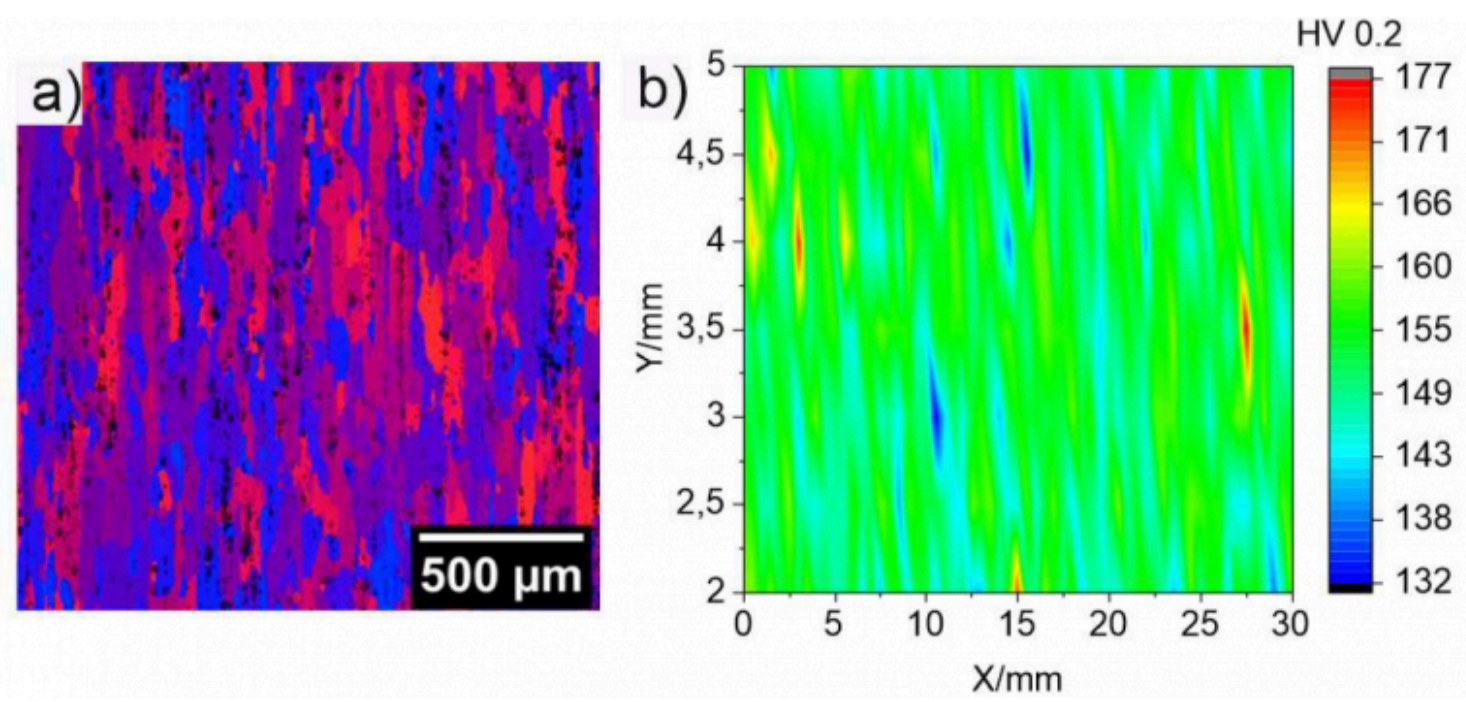

Fig. 1. a) Microstructure and b) microhardness map of the AA 2024-T3 rivet in the extrusion direction.

\subsection{Glass-reinforced Epoxy Resin Laminate (FR4-PCB)}

Glass-reinforced epoxy resin laminates, the most used material for PCB confection, with single copper layer on one side and double copper layer adhered to either board side were used to manufacture the joints. These PCB materials are named FR4 by NEMA (National Electrical Manufacturers Association, USA), where 'FR' stands for flame retardant material [14]. The thickness of the used plates is $1.5 \mathrm{~mm}$, which is among the highest of PCBs commercially produced. The FR4 glass fiber epoxy is the most popular and versatile material used in PCBs, mainly because of the good resistance-weight ratio and the capacity to keep the high mechanical strength and the good insulating in humid environments [15]. Fig. 2 illustrates the FR4 microstructures used in this study, with double (Fig. 2a) and single copper layer (Fig. 2b), alongside the sketch of Cu-layer-FR4 distribution along the material thickness.
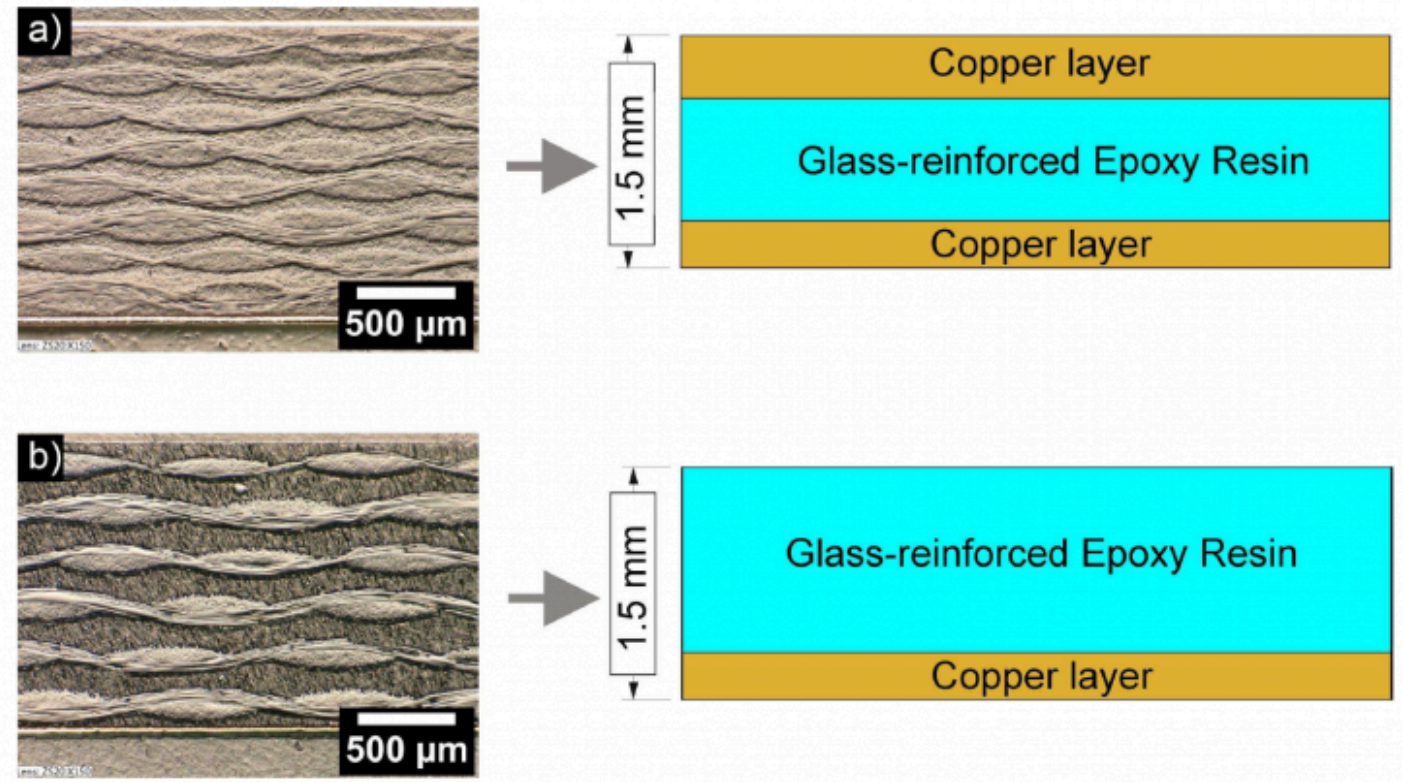
Deformation and Anchoring of AA 2024-T3 rivets within thin printed circuit boards

Fig. 2. The microstructure of glass-fiber-reinforced epoxy laminates (FR4-PCB) with a) double and b) single copper layer, alongside the sketch of Cu-layer-FR4 distribution along the material thickness.

\subsection{Friction Riveting}

The hybrid joints of AA-2024 rivets and FR4-PCB laminates were produced using a Friction Riveting laboratory equipment (RNA, H. Loitz-Robotik, Hamburg, Germany). A sample holder with a pneumatic clamping system (DZF-50-25-P-A-FESTO, Islandia, NY, USA) was used to fix the overlapped FR4 plates. This work adopted a directFriction Riveting process variant controlled by force and limited by spindle displacement [9],[16]. In Fig. 3, the schematic description of the Friction Riveting process is shown. The technique is based on frictional heating, resulting from the rivet rotation and its insertion into polymeric or composite parts (Fig. 3b). Forging force is applied when the metallic rivet tip is plasticized, deformed, and consequently anchored (Fig. 3c), resulting in a consolidated joint (Fig. 3d) [6].
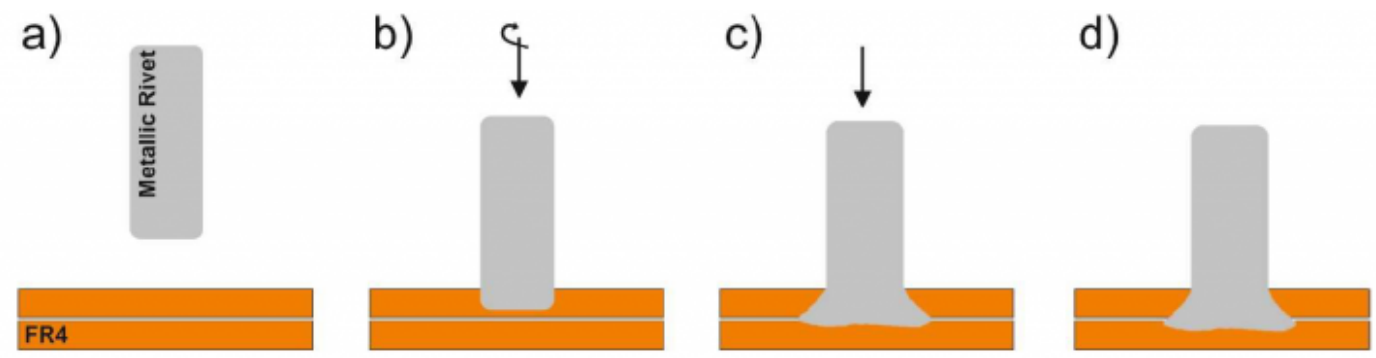

Fig. 3. Schematic description of the Direct Friction Riveting process: a) positioning of jointing partners, b) rivet insertion into the polymer (friction phase), c) rivet plastic deformation (forging phase), and d) joint consolidation.

The joints were produced by varying three main parameters of this process variant: rotational speed (RS), displacement at friction (DaF) and joining force (JF). RS is varied between 6000 - $18000 \mathrm{rpm}$, DaF between $0.50-3.50 \mathrm{~mm}$, and JF from 2000 to 4000 N. A one-factor-a-time (OFAT) approach was applied to obtain a combination of joining parameters until valid joints (deformed and anchored metallic rivet within the FR4-PCB plates) were obtained. Table 2 lists the two finally selected joining conditions investigated further in this work, characterized by a slight difference in the DaF values. The selected joining conditions have the purpose to show the significant difference in deformation and joint formation obtained by different plate stacking configurations and only minimal changes in displacement at friction (as a result of the reduced plate thickness). Condition 1 was applied to four FR4-PCB plates overlapping with double copper layers adhered to either side of the board. Condition 2 was used for two FR4-PCB plates overlapping with a single copper layer adhered to one side (lower side). It has to be noted, that the intention of the work was to produce overlapped joints of two plates. The additional two plates were intended to avoid welding of the rivet to the equipment's working table in case of full perforation.

Table 2. Selected joining conditions investigated in this work. 


\begin{tabular}{ccc}
\hline Parameter & $\begin{array}{c}\text { Condition 1 } \\
\text { (double copper layer) }\end{array}$ & $\begin{array}{c}\text { Condition 2 } \\
\text { (one single copper layer) }\end{array}$ \\
\hline Rotational speed, RS [rpm] & 7000 & 7000 \\
\hline Displacement at friction, DaF [mm] & 3.50 & 3.00 \\
\hline Friction force, FF [N] & 4000 & 4000 \\
\hline
\end{tabular}

\subsection{Joint formation analysis}

The joint formation of the AA2024-FR4-PCB hybrid joints was assessed by optical microscopy (LOM, Keyence VHX-6000, and Leica). The samples were prepared following standard materialography procedures. Mid-cross-section joint images were analyzed via LOM and measurements of the anchoring and deformation geometries were obtained: the maximum width $(\mathrm{W})$ of the deformed rivet tip, its penetration $(\mathrm{H})$ and the anchoring depth $\left(\mathrm{D}_{\mathrm{P}}\right)$ within the FR4-PCB plates. Including the original rivet diameter $D$, these values are used to evaluate the rivet anchoring efficiency by calculating the volumetric ratio (VR). VR describes the rivet anchoring considering the interaction volume between remaining plastic or composite material over the deformed rivet shape [17]:

$$
\mathrm{VR}=\frac{D_{p} \cdot\left(W^{2}-D^{2}\right)}{H \cdot W^{2}}
$$

\subsection{Process temperature evolution, microstructure, and local mechanical properties}

During the joining process, the temperature evolution was recorded on the softened material expelled as flash along the rivet shaft from the joining region employing an infrared camera (Image IR8800, InfraTec, Germany), using a filter gap between $150^{\circ} \mathrm{C}-700^{\circ} \mathrm{C}$. The microstructure was analyzed by $\mathrm{OM}$ and the local mechanical properties were analyzed by Vickers microhardness (ASTM E384-992e1) [18].

\subsection{Global mechanical properties}

The joints' global mechanical performance was investigated through assessment of the ultimate tensile force (UTF) by tensile/pullout testing. Tests were performed using a universal testing machine (100 kN load cell, Zwick Roell 1484, Germany) at room temperature and $1 \mathrm{~mm} / \mathrm{min}$ transverse speed, in type " $\mathrm{T}$ " spot joint configuration, with $40 \mathrm{~mm}$ grip distance. This configuration uses a specially designed specimen holder manufactured, as shown in Fig. 4 [11]. Five samples manufactured from Condition 2 were tested, and their fracture behavior was analyzed. 


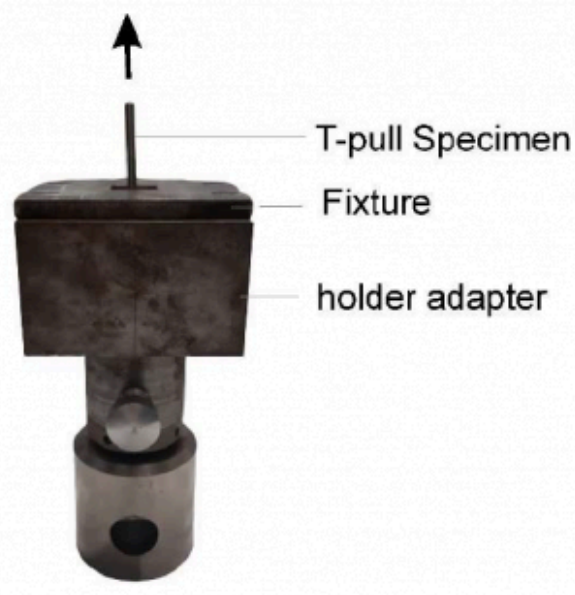

Fig.4. T-pull tensile testing holder adapter used for the evaluation of the tensile force properties in Friction Riveting.

\section{Results}

Fig. 5 presents examples of the assessment of the joints' anchoring zones within the mid-cross-sections for the two investigated parameter sets and material configurations. Three replicates were produced for each condition. The resulting geometrical properties, which characterize the joint formation, are summarized in Table 3. Fig.5a shows a representative joint geometry for Condition 1 (AA-2024-T3 rivet and FR4-PCB double copper layer), where the generated frictional heat resulted in drilling of the rivet through the four FR4-PCB laminates. The metallic rivet achieved $5.5 \pm 0.1 \mathrm{~mm}$ of penetration depth into successive FR4-PCB plates without generating sizeable deformation of the rivet tip $\left(\mathrm{W}=4.8 \pm 0.3 \mathrm{~mm}\right.$, width of initial rivet diameter prior to the joining) and anchoring depth $\left(\mathrm{D}_{\mathrm{P}}=0 \mathrm{~mm}\right)$, resulting in a joint with no volumetric ratio and the perforation of successive FR4 plates, therefore to a not successful Friction Riveting joint. Much improved joints were achieved for Condition 2 (AA-2024-T3 rivet and FR4-PCB single copper layer), see Fig. 5b. The slight change in DaF for Condition 2 had the purpose of reducing the rivet insertion depth to avoid successive penetration of multiple plates. Additionally, it is intended to verify if the heat generated is sufficient to produce significant deformation of the rivet tip into FR4-PCB with less copper layers. The combination of parameters and material configuration achieved heat generation levels sufficient for effective anchoring of the rivet into two FR4-PCB overlapped laminates without perforation of more than two plates. The gap between the two overlapped FR4 plates was caused by the large deformation (from $5.0 \mathrm{~mm}$ to $8.7 \pm 0.8 \mathrm{~mm}$ ). The joints obtained show $2.3 \pm 0.1 \mathrm{~mm}$ penetration, $1.7 \pm 0.1 \mathrm{~mm}$ anchoring depth, and $8.7 \pm 0.8 \mathrm{~mm}$ width deformation. A significant volumetric ratio $(\mathrm{VR}=$ $0.50 \pm 0.02$ ) was achieved at anchoring depths below $3.0 \mathrm{~mm}$, the lowest thickness achieved with the Friction Riveting process so far. 

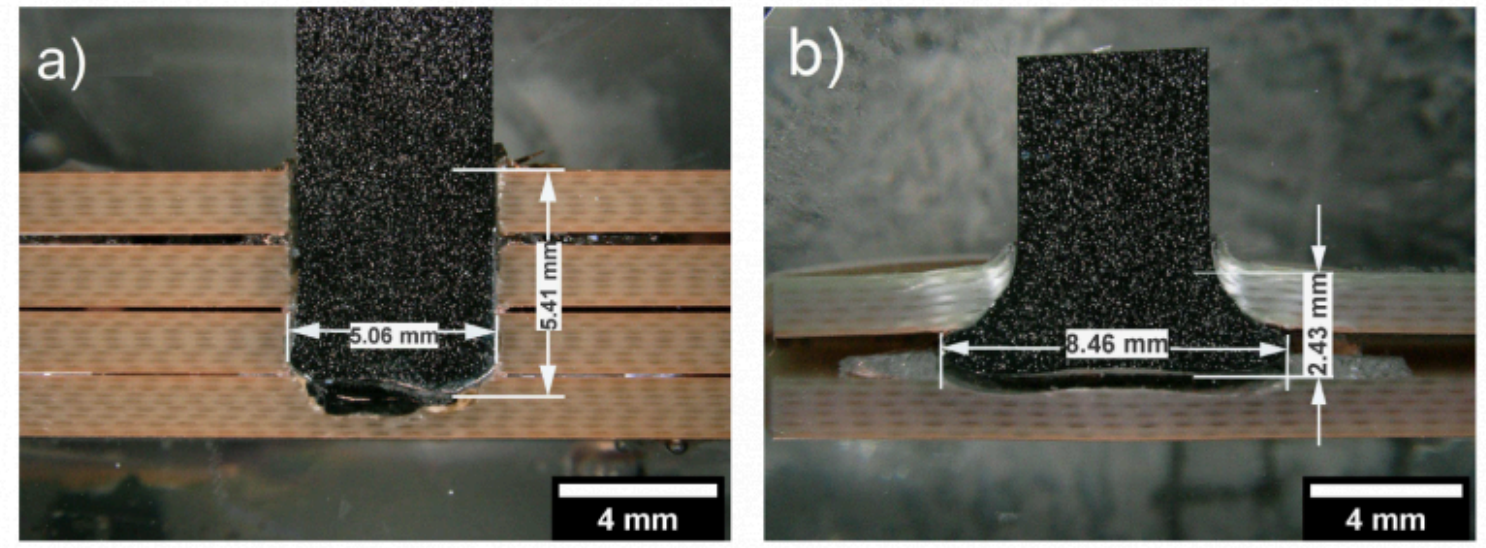

Fig. 5. OM-micrographs of joint cross-sections, produced with the joining conditions 1 and 2 . H-values are related to the penetration depth and $\mathrm{W}$-values to the deformation rivet tip of a) Condition1 (unsuccessful) and b) Condition 2 (successful joint condition).

Table 3. Geometrical features (W, H and DP) of the friction-riveted joints and calculated volumetric ratio, VR.

\begin{tabular}{ccccc}
\hline Joining Condition & $\mathrm{H}[\mathrm{mm}]$ & W[mm] & $\mathrm{D}_{\mathrm{p}}[\mathrm{mm}]$ & VR[a.u] \\
\hline $\begin{array}{c}\text { Condition 1 } \\
\text { (double copper layer) }\end{array}$ & $5.5 \pm 0.1$ & $4.8 \pm 0.3$ & - & - \\
$\begin{array}{c}\text { (RS-7000 rpm; FF-4000 N; DaF-3.5 mm) } \\
\begin{array}{c}\text { Condition 2 } \\
\text { (one single copper layer) }\end{array}\end{array}$ & $2.3 \pm 0.1$ & $8.7 \pm 0.8$ & $1.7 \pm 0.1$ & $0.50 \pm 0.02$ \\
\hline RS-7000 rpm; FF-4000 N; DaF-3.0 mm) & & & & \\
\hline
\end{tabular}

The different joint formations achieved might also be related to the strong anisotropic character of the FR4-PCBs material due to the significant difference between cooper and glass-epoxy thermal properties [19]. The placement of single or double-layer in the board significantly influences the generated heat during the Friction Riveting process, as the process starts with an initial Coulomb friction and subsequent changes in material viscosity during the rivet insertion.

Fig. 6 shows the process temperature measurements via infrared thermography (Fig. 6a) and the average peak temperatures (Fig. 6b) recorded on expelled flash material from three joint replicates manufactured with Condition 2. The average temperature obtained was $362 \pm 7^{\circ} \mathrm{C}$, which is approximately $70 \%$ of the rivet melting temperature, which lies within the range of measured temperatures in friction welding based techniques applied to this alloy [13][20]. The temperature achieved shows that the generated heat is sufficient to promote the rivet deformation despite the minimal material thickness.. 

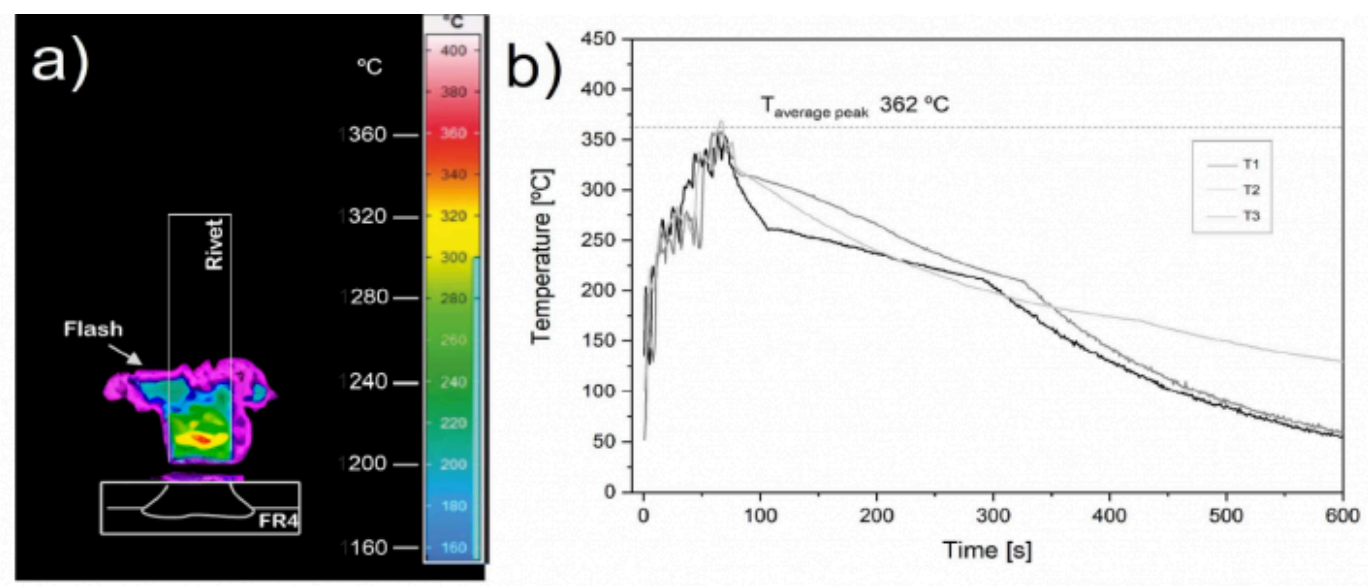

Fig. 6.a) Infrared thermography of the process temperature development during Friction Riveting. b) Maximum average temperature ( $362 \pm 7^{\circ} \mathrm{C}$ ) measured on the expelled thermoset flash material from three joints produced for Condition 2.

Fig. 7a shows the microstructure and the Vickers microhardness distribution of an AA-2024-T351 deformed rivet from the joining condition depicted in Fig. 5b. Different microstructural zones have been identified, similar to the ones obtained in previous studies of friction-riveted AA-2024-T351 joints in thermoplastic materials [11]. It shows that joint formation can be achieved in both thermoplastic and thermosetting polymeric / composite materials. A statement prior considered impossible due to the nature of thermosets and their high flammability and no melting possibility. As shown in the work of Borba et al. [22], this is not the case with the use of additives in thermosetting composites, as is the case for FR4 (mentioned in Section 2.2).

Fig. 7b presents the thermo-mechanically affected zone (TMAZ) of the metallic rivet. A realignment of grains is observed in the direction of the flow of forged and plasticized volume of material. Partial grain refinement is also seen, characteristic for dynamic recrystallization in aluminum alloys, as reported for other friction-based welding processes [23-24] as well. In the metal heataffected zone (HAZ) (Fig. 7c), no visual microstructural changes have been observed (see base material in Fig. 1b). More investigations through electron microscopy are required in order to identify phenomena such as static recovery and re-precipitation [8]. This can be caused by recovery, recrystallization, re-precipitation or averaging [11],[25]. Other friction-based processes like friction stir welding (FSW) lead to similar changes, as demonstrated by Milčić et al. [26]. The undermatching of microhardness in Friction Riveting as well as FSW of AA-2024, generally below $10 \%$, is typically observed [21]. 


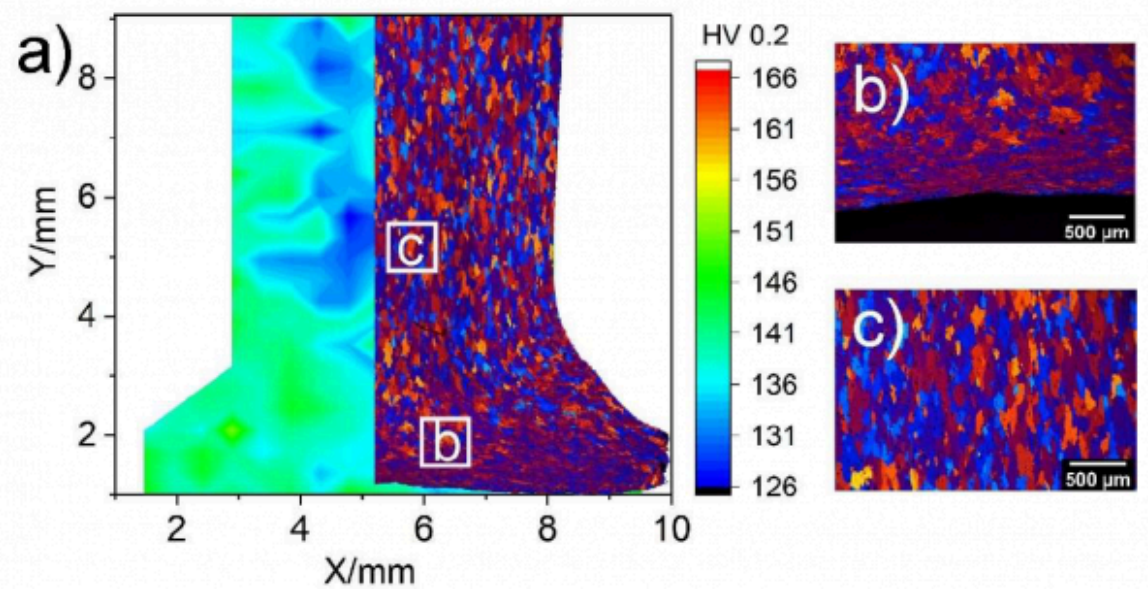

Fig. 7.a) Microstructure features of a Friction-riveted PCB-FR4 single copper layer/AA-2024-T351 joint (Condition 2) and Vickers microhardness distribution of an AA 2024-T3 deformed rivet. b) Thermo-Mechanically Affected Zone of the metal, TMAZ, exhibits grain realignment in the direction of the material flow in the forged rivet tip c) Detail of the Heat Affected Zone of the metal, HAZ.

Rodrigues et al. [8] measured similar temperature ranges performing Friction Riveting process joining AA2024-T3 with polycarbonate and the metal microstructure presented the same transformations after the process. These microstructure changes can be observed in others friction based process as demonstrated by Amancio et al. [21] However, the microhardness (Fig. 7a, left) shows a slight reduction compared to the base material. Changes in microstructure and local reduction of mechanical properties within the metallic rivet might influence the global mechanical behavior of friction riveted joints, as reported previously [8],[9]. Nonetheless, the anchoring efficiency determined by VR is dominant for identifying potential good/weak joints, as it indirectly (metal-composite interface is not considered for VR) considers the interaction of the deformation (both depth and width) with the remaining composite material around and above the anchored deformed rivet [9],[27],[28]. The global mechanical performance of the FR4-PCB-AA-2024-T3 joints was assessed by tensile tests for samples manufactured by Condition 2. The ultimate tensile force is obtained as $828 \mathrm{~N} \pm 65 \mathrm{~N}$, with fracture occurring within the composite base material. A comparison with other combination of materials is not relevant, given that the plate thickness in this study despite being overlapped, is the minimum reported so far for Friction Riveting [29].

Fig. 8b shows the final failure in the FR4-PCB material. Based on previous works [22][8], this type of failure through FR4-PCB occurs due to plate bending, followed by delamination (Fig. 8b and d). Bending tests of FR4-PCB and fracture analysis using SEM will be performed in the future to confirm the features of this failure. Since the anchoring depth was lower than the initial rivet diameter, joint failure within the rivet was not expected, despite the reduction of local mechanical properties in the rivet. The fracture occurring within the composite material and not within the deformation legs nor the weakened metal HAZ proves the soundness of the anchoring efficiency by the VR approach, namely sufficient anchoring was provided to avoid the full extraction of the rivet. Nonetheless, the composite structure might have been affected, therefore further investigations will focus on the structural and physical-chemical changes within the FR4-PCB material as well as the interface between rivet and composite. 

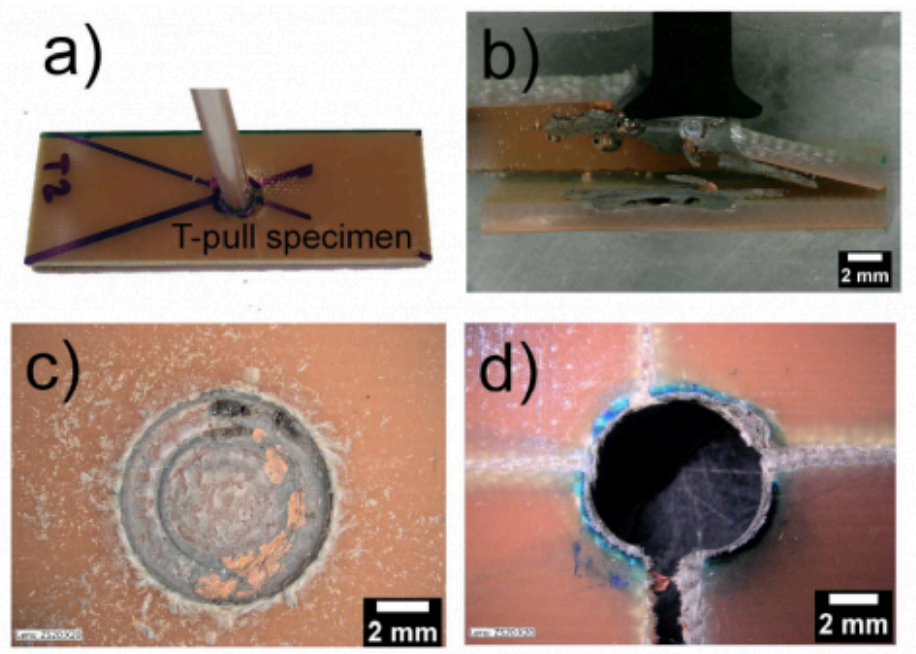

Fig. 8.a) T-pull specimen prior to testing, b) cross-sectional view of failure through PCB plate, (c) lower and (d) upper FR4-PCB parts after T-pull testing.

\section{Summary and Conclusions}

The current work investigated the joint formation and inherent deformation/anchoring of 5 mm diameter AA-2024-T3 rivets within overlapped $1.5 \mathrm{~mm}$ thick glass-fiber-reinforced epoxy plates (FR4-PCB) via Friction Riveting. The first results of the anchorages of AA2024 in FR4-PCB are considered very promising. It was possible to achieve wellanchored joints, with $60 \%$ of the rivet tip deformed at $2.43 \mathrm{~mm}$ penetration depth in the FR4 laminate. The joints present significant anchoring efficiency (volumetric ratio $\mathrm{VR}=0.50 \pm 0.02$ ), achieved at thicknesses and anchoring depths below $3.0 \mathrm{~mm}$, which is considered the lowest depth achieved so far with Friction Riveting. The maximum process temperature (362 $\pm 7^{\circ} \mathrm{C}$, approximately $70 \%$ of the rivet melting temperature) was sufficient for effective deformation and consequently mechanical anchoring of the rivet. The heating and the applied process forces resulted in microstructural changes and reduction of local mechanical properties, with grain refinement and realignment within the deformed rivet tip. The joints' mechanical performance was evaluated in terms of ultimate tensile force, reaching $828 \mathrm{~N} \pm 65 \mathrm{~N}$, with failure occurring through FR4-PCB due to plate bending, followed by delamination. The rivet anchoring was sufficient to withstand the potential full extraction of the deformed metallic insert joint, which was prior demonstrated as the weakest joint behavior in all previously tested material combinations for Friction Riveting. Therefore, the mechanical anchor achieved in this work can be regarded as efficient.

This work constitutes a premiere by showing that it is possible to deform metallic rivets within thin composite plates at diameterto-thickness ratio below 1:1. Further works will investigate in depth the metallurgical changes in AA-2024-T3, the PCB-rivet interface, and the failure mechanisms related to tensile/pullout testing in this combination of materials and similar, alongside the changes in physical-chemical and electrical properties.

\section{Acknowledgements}

This work is supported by the HZG technology transfer fund in cooperation with Panasonic Industrial Devices Europe GmbH within the "FricBoard" project. This support is gratefully acknowledged. 


\section{Bibliography}

[1] R. Sanapala, "Characterization of FR-4 printed circuit board laminates before and after exposure to lead-free soldering conditions," Master's thesis, University of Maryland, 2008.

[2] Würth Eletronik 2017, Press-Fit Technology, Würth Eletronik, viewed 30th March 2020, <https://www.element14.com/community/docs/DOC-66965/l/pressfit-technology>

[3]NP Northern Precision LTD (n.d), Broaching Suds for printed Circuit board, viewed 30th March 2020, <https://www.npfasteners.com/broaching.com/cbfh.htm> [4] Amancio-Filho, S.T. Beyer, M. and Dos Santos, J.F. US 7 575149 B2 - Method of connecting a metallic bolt to a plastic workpiece, U.S. Patent Office, 2009

[5] Amancio-Filho, S.T. Beyer, M. and Dos Santos, J.F. EP 1790462 B1 - Verfahren zum Verbinden eines metallischen Bolzens mit einem Kunststoff-Werkstück, 2011.

[6] Amancio-Filho, S.T. dos Santos, J.F. Henry Granjon Prize Competition 2009, Winner Category A: "Joining and Fabrication Technology" FRICTION RIVETING: Development and Analysis of a New Joining Technique for PolymerMetal Multi-Material Structures. Weld World, 2011, 55:13-24 DOI 10.1007/BF03263511.

[7] Altmeyer, J., dos Santos, J.F., Amancio-Filho, S.T. Effect of the Friction Riveting process parameters on the joint formation and performance of Ti alloy/shortfiber reinforced polyether ether ketone joints. Materials Designer 60:164176, 2014.

[8] Rodrigues, C.F. Blaga L.A. Santos dos, J.F. Canto, L.B. Hage Jr., E. and Amancio-Filho, S.T. FricRiveting of aluminum 2024-T351 and polycarbonate: Temperature evolution, microstructure, and mechanical performance. Journal of Materials Processing Technology, 2014, 214(0):2029 - 2039, 2014.

[9] Proenca, B. Blaga, L.A.Santos, J.F. Canto, L.B. Amancio-Filho, S.T. Force controlled friction riveting of glass fiber reinforced polyamide 6 and aluminum alloy 6056 hybrid joints. In Proceedings of the Annual Technical ConferenceANTEC, 2015

[10] Borba, N. Z. Afonso, C. Blaga, L. A. et al. On the Process-Related Rivet Microstructural Evolution, Material Flow and Mechanical Properties of Ti 6Al4V/GFRP Friction-Riveted Joints. Materials (Basel), 2017, 10:184. D0I/10.3390/ MA10020184

[11] Amancio-Filho, S.T Blaga, L.A. Joining of polymer-metal hybrid structures: principles and applications. John Wiley \& Sons, Inc, Hoboken, NJ, 2018.

[12] Blaga, L.A Bancila, R. Santos, J.F. and Amancio-Filho, S.T. Friction Riveting of glass-fibre-reinforced polyetherimide composite and titanium grade 2 hybrid joints. Materials and Design, 2013, 50:825-829.

[13] ASM Specialty Handbook: Aluminum and Aluminum Alloys, ASM International, Materials Park, OH, USA, 1993.

[14] PCB FR4: the guide to FR-4 for your printed circuits, viewed 9th October 2020, <https://www.protoelectronics.com/blog/the-4-electronic-componentsuppliers-of-proto-electronics-0>.

[15] Materials for printed circuit boards, viewed 9th October $2020<$ http://www.nanotech-elektronik.pl/index.php/ en/info/materials $>$.

[16] Borba, N. Z. Blaga, J.F. dos Santos, S.T. Amancio-Filho, Direct-Friction Riveting of polymer composite laminates for aircraft applications, Materials Letters, Volume 215, 2018, doi.org/10.1016/j.matlet.2017.12.033. 
Deformation and Anchoring of AA 2024-T3 rivets within thin printed circuit boards

[17] Cipriano, P. G. Ahiya, A. dos Santos, J.F. Single-phase Friction Riveting: metallic rivet deformation, temperature evolution, and joint mechanical performance. Weld World, 64: 47-58, 2020. DOI 10.1007/S40194-019-00803-3

[18] ASTM E384-992e1: Test Method for Microindentation Hardness of Material, ASTM International, USA, 2005.

[19] Andonova, A. Kafadarova, N. Pavlov, G. Investigation of thermal conductivity of PCB. Electronics, 2006. DOI10.1109/ ISSE.2009.5207019

[20] Sadeesh, P. Venkatesh Kannan, M. Rajkumar, V. et al. Studies on Friction Stir Welding of AA 2024 and AA 6061 Dissimilar Metals, Procedia Engineering, Volume 75, 2014, Pages 145-149. DOI 10.1016/j.proeng.2013.11.031.

[21] Amancio-Filho, S. T. Camillo, A. P. C. Bergmann, L. et al. Preliminary Investigation of the Microstructure and Mechanical Behavior of 2024 Aluminum Alloy Friction Spot Welds. Materials Transactions, Vol. 52, No. 5 pp. 985 to 991, 2011.

[22] Borba, N. Z. Blaga, L. Canto, L. B. dos Santos, J. F., Amancio-Filho, S. T. Friction Riveting of pultruded thermoset glass fiber reinforced polyester composite and Ti6Al4V hybrid joints, In Proceedings of the Annual Technical Conference, ANTEC, Las Vegas, USA, 2014.

[23] Han, J. Paidar, M. Vignesh, R.V. et al. Effect of shoulder features during friction spot extrusion welding of 2024-T3 to 6061-T6 aluminum alloys. Archiv.Civ.Mech.Eng 20, 84, 2020. DOI 10.1007/s43452-020-00086-2

[24] Goebel J. Reimann, M. Norman, A. Santos dos, J.F. Semi-stationary shoulder bobbin tool friction stir welding of AA2198-T851. Journal of Materials Processing Technology, 245(2017) 37-45, 2017.

[25] Smallman L. E., Nhan A.H.W., Modern Physical Metallurgy, 8th. Ed., Elsevier, 2013

[26] Milčić, M. Vuherer T. Radisavljević, I. Milčić, D. Kramberger, J. Andjelković, B. Mechanical behaviour of Al 2024 alloy welded by friction stir welding, IOP Conference Series: Materials Science and Engineering, 2018.

[27] Cipriano, P. G. Blaga, L. A. dos Santos, J. F. Vilaça P. Amancio-Filho S.T. Fundamentals of Force-Controlled Friction Riveting: Part I-Joint Formation and Heat Development. Materials 2018, 11, 2294; doi:10.3390/ma11112294.

[28] Cipriano, P. G. Blaga, L. A. dos Santos, J. F. Vilaça P. Amancio-Filho S.T. Fundamentals of Force-Controlled Friction Riveting: Part II-Joint Global Mechanical Performance and Energy Efficiency. Materials 2018, 11, 2489; doi:10.3390/ ma11122489.

[29] Amancio-Filho, S.T. Blaga, L. A. Joining of Polymer-Metal Hybrid Structures: Principles and Applications, John Wiley \& Sons, 2018.

PDF automatically generated on 2021-05-20 17:49:58

Article url: https://popups.uliege.be/esaform21/index.php?id=4327

published by ULiège Library in Open Access under the terms and conditions of the CC-BY License (https://creativecommons.org/licenses/by/4.0) 